\title{
Bone metastasis is associated with poor prognosis in metastatic papillary renal cell carcinoma patients treated with first agent angiogenesis inhibitors
}

\author{
Lorenz Haaker, M.D. ${ }^{a}$, Loesia Tryssesoone, M.D. ${ }^{a}$, Inne Renders, M.D. ${ }^{\text {, }}$ \\ Annelies Verbiest, M.D. ${ }^{a}$, Evelyne Lerut, M.D., Ph.D. ${ }^{\mathrm{b}}$, Marcella Baldewijns, M.D., Ph.D. ${ }^{\mathrm{b}}$, \\ Claire Bourgain, M.D. ${ }^{\mathrm{c}}$, Eduard Roussel, M.D. ${ }^{\mathrm{d}}$, Heidi Van den Bulck, M.D. ${ }^{\mathrm{e}}$, \\ Wim Wynendaele, M.D., Ph.D. ${ }^{\mathrm{e}}$, Brigitte Laguerre, M.D. ${ }^{\mathrm{f}}$, \\ Nathalie Rioux-Leclercq, M.D., Ph.D. ${ }^{\mathrm{g}}$, Stéphane Oudard, M.D., Ph.D. ${ }^{\mathrm{h}}$, \\ Annouschka Laenen, M.Sc. ${ }^{\mathrm{i}}$, Philip R. Debruyne, M.D., Ph.D. ${ }^{\mathrm{j}, \mathrm{k}}$, \\ Maarten Albersen, M.D., Ph.D. ${ }^{\mathrm{d}}$, Benoit Beuselinck, M.D., Ph.D. ${ }^{\mathrm{a}, *}$ \\ ${ }^{a}$ Department of General Medical Oncology, University Hospitals Leuven, Leuven Cancer Institute, Leuven, Belgium \\ ${ }^{\mathrm{b}}$ Department of Pathology, University Hospitals Leuven, Leuven, Belgium \\ ${ }^{\mathrm{c}}$ Department of Pathology, Imelda Ziekenhuis, Bonheiden, Belgium \\ ${ }^{\mathrm{d}}$ Department of Urology, University Hospitals Leuven, Leuven, Belgium \\ ${ }^{\mathrm{e}}$ Department of Medical Oncology, Imelda Ziekenhuis, Bonheiden, Belgium \\ ${ }^{\mathrm{f}}$ Department of Medical Oncology, Centre Eugène Marquis, Rennes, France \\ ${ }^{\mathrm{g}}$ Department of Pathology, CHU de Rennes, Rennes, France \\ ${ }^{\mathrm{h}}$ Department of Medical Oncology, Georges Pompidou European Hospital, Paris, France \\ ${ }^{\mathrm{i}}$ Biostatistics and Statistical Bioinformatics Center, Leuven, Belgium \\ ${ }^{\mathrm{j}}$ Department of Medical Oncology, AZ Groeninge, Kortrijk, Belgium \\ ${ }^{\mathrm{k}}$ Faculty of Health, Education, Medicine \& Social Care, Anglia Ruskin University, Chelmsford, United Kingdom
}

Received 11 February 2020; received in revised form 25 March 2020; accepted 27 April 2020

\begin{abstract}
Objective: Papillary renal cell carcinoma (papRCC) is a rare $(10 \%-15 \%)$ subtype of renal cancer. Few prognostic biomarkers have been described in metastatic papRCC (m-papRCC) patients treated with vascular endothelial growth factor receptor tyrosine kinase inhibitors (VEGFR-TKIs). We aimed to study the prognostic impact of bone metastases (BM) on response rate, progression-free and overall survival (PFS and OS) in patients with m-papRCC treated with first agent VEGFR-TKIs.

Patients and methods: A multicentric, retrospective analysis of patient records was conducted. BM were detected by computed tomography and/or bone scintigraphy. The International Metastatic RCC Database Consortium (IMDC) score was calculated at start of first agent VEGFR-TKI treatment.

Results: Forty-nine patients were included. Best objective response was partial response in $20 \%$, stable disease in $60 \%$ and early progressive disease in $20 \%$ of patients. Median PFS (mPFS) was 6.0 months and median OS (mOS) 14.0 months after start of first agent VEGFR-TKI. The IMDC score correlated with mOS: 77.5 months in good, 17.0 months in intermediate and 8.0 months in poor risk patients $(P=0.002)$. Patients with BM had a poorer outcome compared to patients without BM: mPFS was 4.0 vs. 7.0 months $(P=0.006)$ and mOS 7.5 vs. 19.0 months $(P=0.002)$. On bivariate analysis, the presence of BM was independently associated with PFS $(P=0.02)$ and OS $(P=0.049)$, independent of the IMDC risk groups.
\end{abstract}

\footnotetext{
Benoit Beuselinck is senior clinical investigator of the Fonds voor Wetenschappelijk Onderzoek Vlaanderen (Belgium) grant (1801520N). Annelies Verbiest received a Fonds voor Wetenschappelijk Onderzoek Vlaanderen (Belgium) grant (1121619N). Eduard Roussel received an IPSEN research grant.
}

\footnotetext{
*Corresponding author. Tel.: +32-16-346900; fax: +32-16-346901. E-mail address: benoit.beuselinck@uzleuven.be (B. Beuselinck).
} 
Conclusion: In m-papRCC patients treated with first agent VEGFR-TKIs, the presence of BM is an unfavorable prognostic factor, associated with shorter PFS and OS. (C) 2020 Elsevier Inc. All rights reserved.

Keywords: Papillary renal cell carcinoma; Bone metastases; Prognostic factors; Angiogenesis inhibitors

\section{Introduction}

Renal cell carcinoma (RCC) accounts for about $2.2 \%$ of all cancers and $1.8 \%$ of all cancer deaths worldwide [1]. The most frequent (85\%) histologic subtype is clear-cell RCC (ccRCC) whereas $10 \%$ to $15 \%$ are papillary RCCs (papRCC) [2]. papRCC can be further classified in type 1 and type 2 papRCC. Other rare RCC subtypes are, among others, chromophobe RCCs, Bellini Duct carcinomas and medullary RCCs. All these subtypes, except ccRCCs, are defined as non-ccRCCs.

Most patients with papRCC present with localized disease and are treated with (partial) nephrectomy with curative intent. However, a considerable number will eventually relapse. Up to one third of patients present with metastatic papRCC (m-papRCC). For most m-papRCC patients, systemic therapies are eventually indicated. Globally, mpapRCC has a worse prognosis than metastatic ccRCC (mccRCC) [3] and before the era of vascular endothelial growth factor receptor (VEGFR)-targeted therapies, outcome in m-papRCC was very poor [4]. Therapies targeting the VEGFR, such as the tyrosine kinase inhibitors (TKI) sorafenib and sunitinib, have proven effective in $\mathrm{m}$ papRCC [5-8]. However, efficacy of VEGFR-TKI therapy is lower in m-papRCC compared to m-ccRCC [3]. A large subgroup of papRCCs is characterized by cMET overexpression and amplification or activating mutations. Specific cMET inhibitors such as savolitinib and crizotinib $[9,10]$ and TKIs inhibiting both the VEGFR and cMET such as foretinib and cabozantinib [11,12] are active against $\mathrm{m}$ papRCCs. More recently, the first positive results with immune checkpoint inhibitors have been presented in nonccRCCs [13]. In a study published before the approval of VEGFR-TKIs in RCC, 5-year cancer specific survival rates were significantly better for type $1(n=34)$ compared to type $2(n=62)$ papRCCs $(94 \%$ vs. $74 \%, P=0.03)$ [14].

As m-papRCC is a rare disease, few prognostic biomarkers have been described in these patients, whereas in $\mathrm{m}$-ccRCC, several biomarkers and prognostic scores are available. The most commonly used prognostic score system in metastatic RCC (mRCC) is the International Metastatic Renal Cell Carcinoma Database Consortium (IMDC) score, developed in the era of VEGFR-targeted therapies. Initially developed in a mixed group of histology (94.1\% ccRCC and $5.9 \%$ non-ccRCC), the IMDC score is mainly used in m-ccRCC patients [15]. However, some evidence also exists that the IMDC prognostic score is valid in $\mathrm{m}$ papRCC patients [16].
In m-ccRCC, the negative prognostic impact of bone metastases (BM) has clearly been shown in several large studies $[17-19]$. Therefore, we aimed to assess the prognostic impact of BM in m-papRCCs treated with VEGFRTKIs.

\section{Patients and methods}

We conducted a retrospective review of the records of all m-papRCC patients who started first agent VEGFR-TKIs between May 2006 and November 2017 at the University Hospitals Leuven and general hospital Groeninge in Kortrijk and general hospital Imelda in Bonheiden. We also included patients with m-papRCC from our international French-Belgian CIT-rein tumor bank. All patients were treated in routine clinical practice. Timing, dose-reduction and schedule were left to the discretion of the attending doctors in accordance with applicable local and international practice guidelines at time of treatment. Follow-up computed tomography (CT) was foreseen every 8 to 12 weeks on therapy. The study was approved by the ethics committees of the different institutions.

All pathology samples were analyzed by a senior genitourinary pathologist (EL, MB, CB, and NRL). Outcome parameters were best response (according to Response Evaluation Criteria in Solid Tumors RECIST), progressionfree survival (PFS) and overall survival (OS) from start of first agent VEGFR-TKI. We calculated the IMDC prognostic score at start of first agent VEGFR-TKI treatment. The presence of BM was detected by CT-scan of thorax and abdomen and/or bone scintigraphy per standard of care. In case of local complaints in the limbs, more oriented radiologic examinations were performed.

In descriptive analyses, groups were compared with the unpaired t-test for continuous variables. Categorical variables were compared using the Fisher's exact test. Kaplan-Meier estimates were used to estimate PFS and OS. Univariable and multivariable Cox proportional hazards models were used to investigate associated factors. Results are presented as hazard ratios with $95 \%$ confidence intervals (CI). Analyses were performed using GraphPad Prism (GraphPad, San Diego, CA) and SAS software (version 9.4 of the SAS System for Windows developed by SAS Institute; Cary, NC).

\section{Results}

We included 49 eligible patients in our analysis (Leuven: 30, Bonheiden: 6, Kortrijk: 7, Rennes: 5, Angers: 1). Patient 
Table 1

Patient characteristics

\begin{tabular}{|c|c|c|c|c|}
\hline & Total series & Without BM & With BM & $P$ \\
\hline \multicolumn{5}{|l|}{ Patient characteristics at diagnosis } \\
\hline Number of patients & 49 & 31 & 18 & \\
\hline Mean age at diagnosis (years)(range) & $61.6(25-83)$ & $61.3(25-79)$ & $62.1(32-83)$ & 0.83 \\
\hline Male sex & $44 / 49(89.8 \%)$ & $28 / 31(90.3 \%)$ & $16 / 18(88.9 \%)$ & $>0.99$ \\
\hline Nephrectomy at diagnosis & $40 / 49(81.6 \%)$ & $25 / 31(80.7 \%)$ & $15 / 18(83.3 \%)$ & $>0.99$ \\
\hline M1 at diagnosis (synchronous metastases) & $24 / 48(50 \%)$ & $15 / 30(50 \%)$ & $9 / 18(50 \%)$ & $>0.99$ \\
\hline \multicolumn{5}{|l|}{ Fuhrman } \\
\hline Grade 1-3 & $23 / 42(54.8 \%)$ & $13 / 24(54.2 \%)$ & $10 / 18(55.6 \%)$ & $>0.99$ \\
\hline Grade 4 & $19 / 42(45.2 \%)$ & $11 / 24(45.8 \%)$ & $8 / 18(44.4 \%)$ & \\
\hline \multicolumn{5}{|l|}{ Histology type } \\
\hline papRCC type 1 & $11 / 49(22.4 \%)$ & $10 / 31(32.3 \%)$ & $1 / 18(5.6 \%)$ & 0.04 \\
\hline papRCC type 2 & $32 / 49(65.3 \%)$ & $16 / 31(51.6 \%)$ & $16 / 18(88.9 \%)$ & 0.01 \\
\hline papRCC type $1+2$ & $2 / 49(4.1 \%)$ & $2 / 31(6.5 \%)$ & $0 / 18(0 \%)$ & 0.53 \\
\hline Unknown & $4 / 49(8.2 \%)$ & $3 / 31(9.7 \%)$ & $1 / 18(5.6 \%)$ & $>0.99$ \\
\hline \multicolumn{5}{|l|}{ Patient characteristics at start of targeted therapy } \\
\hline Karnofsky $<80$ & $30 / 49(61.2 \%)$ & $18 / 31(58.1 \%)$ & $12 / 18(66.7 \%)$ & 0.76 \\
\hline Neutrophils $>$ ULN & $7 / 48(14.6 \%)$ & $3 / 30(10 \%)$ & $4 / 18(22.2 \%)$ & 0.40 \\
\hline Anemia $(\mathrm{Hb}<14.0 \mathrm{~g} / \mathrm{dl}$ in men and $<12.0 \mathrm{~g} / \mathrm{dl}$ in women $)$ & $34 / 49(69.4 \%)$ & $16 / 31(51.6 \%)$ & $18 / 18(100 \%)$ & 0.0002 \\
\hline LDH elevated $>1.5 x$ ULN & $8 / 49(16.3 \%)$ & $3 / 31(10.7 \%)$ & $5 / 18(27.8 \%)$ & 0.12 \\
\hline Corrected calcium elevated $>10.2 \mathrm{mg} / \mathrm{dl}$ & $4 / 33(12.1 \%)$ & $2 / 17(11.8 \%)$ & $2 / 16(12.5 \%)$ & $>0.99$ \\
\hline CRP elevated $>5 \mathrm{mg} / \mathrm{L}$ & $32 / 41(78 \%)$ & $19 / 26(73.1 \%)$ & $13 / 15(86.7 \%)$ & 0.45 \\
\hline Albumin decreased $<\mathrm{LLN}$ & $7 / 35(20 \%)$ & $3 / 19(15.8 \%)$ & $4 / 16(25 \%)$ & 0.68 \\
\hline Interval from diagnosis to targeted therapy $<12$ months & $31 / 49(63.3 \%)$ & $19 / 31(61.3 \%)$ & $12 / 18(66.7 \%)$ & 0.77 \\
\hline Immunotherapy before targeted therapy (IFN \pm IL2) & $5 / 49(10.2 \%)$ & $2 / 31(6.5 \%)$ & $3 / 18(16.7 \%)$ & 0.34 \\
\hline \multicolumn{5}{|l|}{ Therapy before VEGFR-TKI } \\
\hline Chemotherapy & $3 / 49(6.1 \%)$ & $1 / 31(3.2 \%)$ & $2 / 18(11.1 \%)$ & 0.55 \\
\hline Crizotinib & $1 / 49(2.0 \%)$ & $1 / 31(3.2 \%)$ & $0 / 18(0 \%)$ & 1.00 \\
\hline Everolimus/temsirolimus & $4 / 49(8.2 \%)$ & $0 / 31(0 \%)$ & $4 / 18(22.2 \%)$ & 0.01 \\
\hline Total & $8 / 49(16.3 \%)$ & $2 / 31(6.5 \%)$ & $6 / 18(33.3 \%)$ & 0.04 \\
\hline \multicolumn{5}{|l|}{ Site of metastasis } \\
\hline Liver & $13 / 49(26.5 \%)$ & $7 / 31(22.6 \%)$ & $6 / 18(33.3 \%)$ & 0.51 \\
\hline Lung & $27 / 49(55.1 \%)$ & $16 / 31(51.6 \%)$ & $11 / 18(61.1 \%)$ & 0.57 \\
\hline Bone & $18 / 49(36.7 \%)$ & $0 / 31(0 \%)$ & $18 / 18(100 \%)$ & NA \\
\hline Brain & $1 / 49(2.0 \%)$ & $0 / 31(0 \%)$ & $1 / 18(5.6 \%)$ & 0.37 \\
\hline Lymph nodes & $39 / 49(79.6 \%)$ & $23 / 31(74.2 \%)$ & $16 / 18(88.9 \%)$ & 0.29 \\
\hline Mean number of metastatic sites & 2.61 & 2.19 & 3.33 & 0.003 \\
\hline \multicolumn{5}{|l|}{ IMDC prognostic score } \\
\hline Favourable & $3 / 49(6.1 \%)$ & $3 / 31(9.7 \%)$ & $0 / 18(0 \%)$ & 0.29 \\
\hline Intermediate & $24 / 49(49.0 \%)$ & $18 / 31(58.1 \%)$ & $6 / 18(33.3 \%)$ & 0.14 \\
\hline Poor & $22 / 49(44.9 \%)$ & $10 / 31(32.3 \%)$ & $12 / 18(66.7 \%)$ & 0.036 \\
\hline \multicolumn{5}{|l|}{ First agent VEGFR-TKI } \\
\hline Axitinib & $1 / 49(2.0 \%)$ & $0 / 31(0 \%)$ & $1 / 18(5.6 \%)$ & 0.37 \\
\hline Pazopanib & $10 / 49(20.4 \%)$ & $7 / 31(22.6 \%)$ & $3 / 18(16.7 \%)$ & 0.73 \\
\hline Sorafenib & $4 / 49(8.2 \%)$ & $0 / 31(0 \%)$ & $4 / 18(22.2 \%)$ & 0.014 \\
\hline Sunitinib & $34 / 49(69.4 \%)$ & $24 / 31(77.4 \%)$ & $10 / 18(55.6 \%)$ & 0.12 \\
\hline
\end{tabular}

papRCC = papillary renal cell carcinoma; IMDC = International Metastatic Renal Cell Carcinoma Database Consortium; ULN = upper limit of normal; $\mathrm{LDH}=$ lactate dehydrogenase; $\mathrm{CRP}=\mathrm{C}$-reactive protein; $\mathrm{LLN}=$ lower limit of normal; IFN = interferon; IL2 = interleukin-2; $\mathrm{BM}=$ bone metastases; The IMDC score is calculated based on the presence of 6 clinical and biochemical characteristics: low Karnofsky performance status $(<80)$, short time from original diagnosis to initiation of targeted therapy ( $<1$ year), hemoglobin less than the lower limit of normal, elevated serum calcium levels, high neutrophil and high platelet counts. We used the cut-offs of lower and upper limit of normal as used at the University Hospitals Leuven, where most of the patients were included: hemoglobin $<14 \mathrm{mg} / \mathrm{dl}$ in men and $<12 \mathrm{mg} / \mathrm{dl}$ in women, calcium $>10.2 \mathrm{mg} / \mathrm{dl}$, neutrophils $>7,800 / \mathrm{mm}^{3}$ and platelets $>450,000 / \mathrm{mm}^{3}$. Patients without any risk factor are considered to have good prognosis, while patients with one or two risk factors are considered to have intermediate prognosis and individuals with three or more risk factors poor prognosis [14].

Significant $\mathrm{p}$-values $(\mathrm{p}<0.05)$ are in bold.

characteristics are shown in Table 1. Eleven patients had type 1 papRCC, 32 patients had type 2 papRCC, and 2 patients had a combination of type 1 and type 2 papRCC. In 4 patients, the subtype was not specified. Before start of first agent VEGFR-TKI, 5 patients received immunotherapy (Interferon with or without interleukine-2), 3 patients received chemotherapy (vinblastine in 2 patients, doxorubicine/gemcitabine in 1 patient), 4 patients received a mammalian target of rapamycin (mTOR)-inhibitor and 1 patient received crizotinib, a cMET-, ALK-, and ROS1-inhibitor. First agent VEGFR-TKI was sunitinib $(n=34)$, pazopanib $(n=10)$, sorafenib $(n=4)$, or axitinib $(n=1)$. The most 
common site of metastasis were the lymph nodes (79.6\%), followed by lung $(55.1 \%)$ and bone $(36.7 \%)$. Eighteen patients out of 49 had BM. BM had an osteolytic appearance in all cases. Patients with BM had a higher mean number of metastatic sites (3.33 vs. 2.19 in patients without $\mathrm{BM}, P=0.003)$. BM tended to appear early in the spread of the disease: in 5 patients, BM appeared before visceral metastases and in 7 patients, BM appeared together with visceral metastases. Only in 2 cases, BM appeared after visceral metastases. In the 4 other patients, this information was not available. The precise number of BM was known in 12 patients. Five patients had a single BM, 2 had 3 BM and 2 had $6 \mathrm{BM}$. The other patients had 2, 11, or more than $25 \mathrm{BM}$. BM were more frequent in type $2 \mathrm{~m}$-papRCC (in 16 out of 32 patients; $50 \%$ ) than in type $1 \mathrm{~m}$-papRCC patients (in 1 patient out of $11 ; 9 \% ; P=0.03$ ). Patients with $\mathrm{BM}$ had received more often $(33.3 \%$ vs. $6.5 \% ; P=0.04)$ systemic therapy before first agent VEGFR-TKI compared to patients without BM. However, in 4 cases out of 8 , this was a short course (mean 3 months) of a mTOR inhibitor (everolimus or temsirolimus), known to have reduced activity in papRCC. The vast majority of patients started at the recommended dose. Only one patient started at a reduced dose of sunitinib $(25 \mathrm{mg} / \mathrm{d})$, but the information was missing in some patients. Time-to-first-dose-reduction as estimated by Kaplan-Meier in the group of patients with and without BM was similar $(P=0.68)$.

At time of analysis, progression was reached in 44 patients (89.8\%) and death in 45 patients $(91.8 \%)$. In the total series, best response was partial response (PR) in $20 \%$, disease stabilization in $60 \%$, and early progressive disease (PD) in $20 \%$ of patients. mPFS was 6.0 months $(95 \%$ CI
4.0-10.0 months) and mOS 14.0 months (95\% CI 9.0 -19.0 months). One, 2, and 3-year PFS rate was 31\%, $8 \%$, and $3 \%$ and 1-, 2- and 3 -year OS rate $53 \%, 22 \%$, and $15 \%$. mPFS was 4.0 months in type 1 and 6.0 months in type 2 m-papRCC $(P=0.32)$, while mOS was 19.0 months in type 1 and 14.5 months in type 2 m-papRCCs $(P=0.36)$. RR was $10 \%$ in type 1 and $27 \%$ in type 2 papRCCs $(P=0.4)$. Among distinct consecutive therapies, cabozantinib was used in 5 and nivolumab in 10 patients.

We confirmed the prognostic impact of the IMDC risk classification in m-papRCC patients: OS was significantly better in good vs. intermediate vs. poor risk patients (mOS 77.5 vs. 17.0 vs. 8.0 months; $P=0.002$ ). Similar differences were found for PFS, but the p-value was slightly above 0.05 (Table 2 and Fig. 1, panel A and B). On univariate analysis, the presence of BM correlated with PFS (mPFS 4.0 vs. 7.0 months, $P=0.006$ ) and OS (mOS 7.5 vs. 19.0 months, $P=0.002$; Table 2 and Fig. 2, panel A and B). PR rate was $20 \%$ in both subgroups. Early PD as best response occurred in $33 \%$ of patients with $\mathrm{BM}$ and in $13 \%$ of patients without BM $(P=0.14)$. On bivariate analysis, the IMDC score $(P=0.03)$ and the presence of BM $(P=0.049)$ were independently correlated with OS. The presence of $\mathrm{BM}$ $(P=0.02)$, but not IMDC score $(P=0.24)$, was also independently correlated with PFS. The number of BM was not related to outcome.

The concomitant use of BRIs was well documented in 17 patients with BM. Seven patients did not receive and 10 patients received BRIs (bisphosphonates: 7; denosumab: 3). Outcome was similar in these 2 subgroups in terms of RR (14\% vs. $10 \%)$, PFS (3.5 vs. 5.0 months; $P=0.38)$ and OS (7.0 vs. 9.0 months; $P=0.24)$.

Table 2

Outcome and prognostic biomarkers

\begin{tabular}{|c|c|c|c|c|c|c|}
\hline & \multicolumn{3}{|c|}{ PFS } & \multicolumn{3}{|c|}{ OS } \\
\hline & Median $(95 \% \mathrm{CI})$ & $\mathrm{HR}(95 \% \mathrm{CI})$ & $P$ & Median $(95 \% \mathrm{CI})$ & $\mathrm{HR}(95 \% \mathrm{CI})$ & $P$ \\
\hline \multicolumn{7}{|l|}{ UNIVARIATE ANALYSIS } \\
\hline $\begin{array}{l}\text { IMDC } \\
\text { Good risk }\end{array}$ & $\begin{array}{l}30.0 \\
(4.0-30.0)\end{array}$ & $\begin{array}{l}1.587 \\
(0.963-2.613)\end{array}$ & 0.07 & $\begin{array}{l}77.5 \\
(76.0-79.0)\end{array}$ & $\begin{array}{l}2.251 \\
(1.350-3.752)\end{array}$ & 0.002 \\
\hline IMDC Intermediate risk & $\begin{array}{l}7.0 \\
(5.0-13.0)\end{array}$ & & & $\begin{array}{l}17.0 \\
(9.0-20.2)\end{array}$ & & \\
\hline $\begin{array}{l}\text { IMDC } \\
\text { Poor risk }\end{array}$ & $\begin{array}{l}3.5 \\
(2.0-12.0)\end{array}$ & & & $\begin{array}{l}8.0 \\
(4.0-14.0)\end{array}$ & & \\
\hline No BM & $\begin{array}{l}7.0 \\
(5.0-14.0)\end{array}$ & $\begin{array}{l}2.548 \\
(1.306-4.973)\end{array}$ & 0.006 & $\begin{array}{l}19.0 \\
(10.0-22.0)\end{array}$ & $\begin{array}{l}2.784 \\
(1.473-5.264)\end{array}$ & 0.002 \\
\hline $\mathrm{BM}$ & $\begin{array}{l}4.0 \\
(2.0-6.0)\end{array}$ & & & $\begin{array}{l}7.5 \\
(4.0-14.0)\end{array}$ & & \\
\hline \multicolumn{7}{|l|}{ BIVARIATE ANALYSIS } \\
\hline IMDC risk & - & $\begin{array}{l}1.366 \\
(0.813-2.294)\end{array}$ & 0.24 & - & $\begin{array}{l}1.849 \\
(1.066-3.206)\end{array}$ & 0.03 \\
\hline $\mathrm{BM}$ & - & $\begin{array}{l}2.251 \\
(1.123-4.512)\end{array}$ & 0.02 & - & $\begin{array}{l}1.988 \\
(1.001-3.946)\end{array}$ & 0.049 \\
\hline
\end{tabular}

IMDC = International Metastatic Renal Cell Carcinoma Database Consortium; PFS = progression-free survival; OS = overall survival HR = hazard ratio; $\mathrm{CI}=$ confidence interval; $\mathrm{BM}=$ bone metastases . 
A

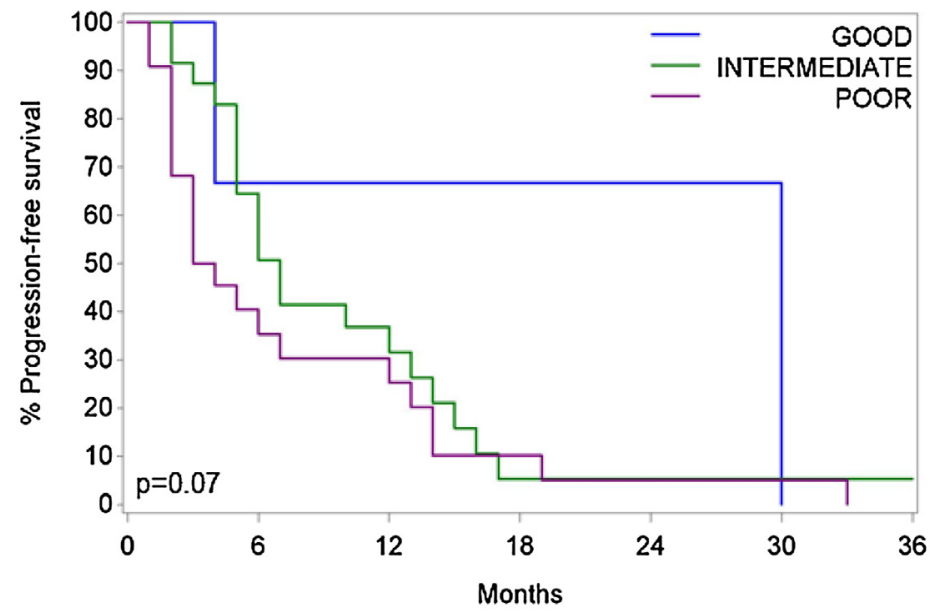

\begin{tabular}{|lrrrrrrr|}
\hline Number at risk & & & & & & & \\
GCOD & 3 & 2 & 2 & 1 & 1 & 1 & 0 \\
INTERMEIATE & 24 & 14 & 7 & 1 & 1 & 1 & 0 \\
POOR & 22 & 8 & 6 & 2 & 1 & 1 & 0 \\
\hline
\end{tabular}

B

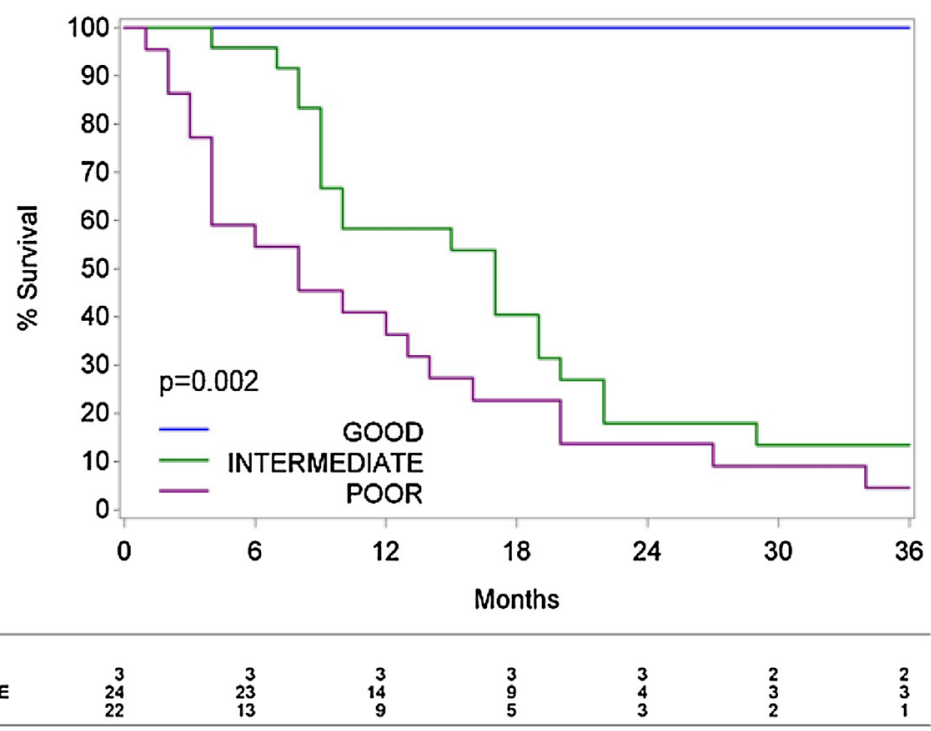

Fig. 1. Prognostic impact of the IMDC risk groups: Kaplan-Meier estimates for progression-free survival (panel A) and overall survival (panel B)

However, baseline prognosis was more favorable in patients who did not receive BRIs (IMDC intermediate risk: $43 \%$; IMDC poor risk: $57 \%$ ) than in patients who received BRIs (IMDC intermediate risk: 20\%; IMDC poor risk: $80 \%$ ).

In order to study the hypothesis that increased incidence of $\mathrm{BM}$ would be the driver behind the more aggressive behavior of type 2 papRCCs, we performed an additional bivariate analysis on 43 patients with available data including the presence of BM and subtype of papRCC. Both the presence of $\mathrm{BM}(P=0.005)$ and the subtype $(P=0.04)$ remained independently associated with OS. In a multivariate analysis including the presence of BM, the IMDC risk score and the histologic subtype of papRCC, only the presence of BM remained as independently associated with OS $(P=0.03)$.

\section{Discussion}

Few prognostic biomarkers have been described in $\mathrm{m}$ papRCC patients treated with VEGFR-targeted therapies. $\mathrm{BM}$ are an unfavorable prognostic factor in m-ccRCC patients treated with angiogenesis inhibitors. We aimed to study the prognostic impact of BM in m-papRCC patients.

In our patient series, we confirmed the global poor performance of VEGFR-TKIs in m-papRCC: mPFS was only 6 months and mOS 14 months. Several other studies have shown the poor outcome of m-papRCC patients treated with VEGFR-TKIs (Table 3). However, data are scarce, because most studies included patients with several histological subtypes other than ccRCCs (defined as nonccRCCs) and did not focus on papRCCs. In the SUPAP trial, studying efficacy of sunitinib in m-papRCCs, a PR rate of $13 \%$, a mPFS of 5.5 months and a mOS of 12.4 


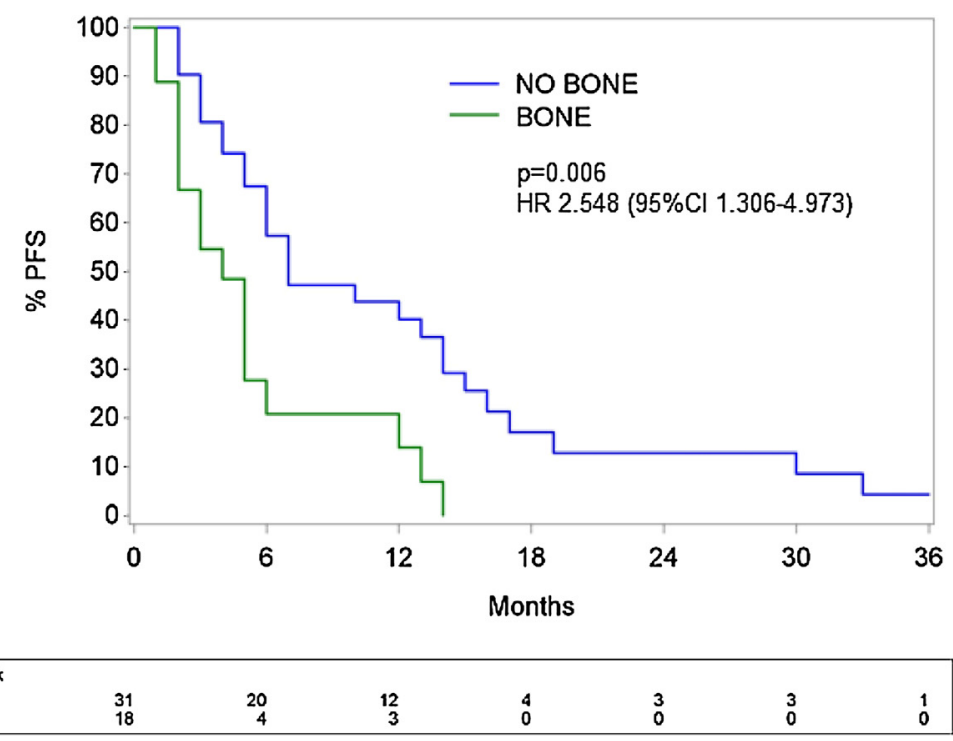

\begin{tabular}{|llcccccc|}
\hline $\begin{array}{l}\text { Number at risk } \\
\text { No BONE }\end{array}$ & 31 & 20 & 12 & 4 & 3 & 3 & 1 \\
BONE & 18 & 4 & 3 & 0 & 0 & 0 & 0 \\
\hline
\end{tabular}



\begin{tabular}{|llllllll|}
\hline $\begin{array}{l}\text { Number at risk } \\
\text { NOBONE }\end{array}$ & 31 & & & & & & \\
BONE & 18 & 11 & 20 & 15 & 7 & 6 & 6 \\
\hline
\end{tabular}

Fig. 2. Prognostic impact of the presence of bone metastases: Kaplan-Meier estimates for progression-free survival (panel A) and overall survival (panel B)

months for 46 patients with type $2 \mathrm{~m}$-papRCC were found [7]. For 15 patients with type $1 \mathrm{~m}$-papRCC, PR rate was $11 \%$, mPFS 6.6 months and mOS 17.8 months. In the ESPN trial, a mPFS of 5.7 months and a mOS of 16.6 months were observed in the subgroup of $14 \mathrm{~m}$-papRCC patients treated with sunitinib [8]. Finally, in the ASPEN trial, $33 \mathrm{~m}$-papRCC patients were treated with sunitinib: mPFS was 8.1 months and PR rate $24 \%$ [6]. The largest retrospective series has been published by the IMDC. In 372 m-papRCC patients treated with first-line VEGF-targeted therapies (mostly sunitinib, but also sorafenib, pazopanib and bevacizumab), mPFS was 4.9 months and mOS 13.9 months, with only $11.9 \%$ of the patients achieving either complete or PR [3]. Note that a large part of the patients in our cohort was also included in the IMDC database. In a retrospective study, Martinez-Chanza et al. observed a PR rate of $27 \%$, a median time-to-treatment failure of 6.9 months and a 12-month OS rate of $46 \%$ in 66 m-papRCC patients treated with cabozantinib. Note that cabozantinib was mostly used in second or further therapy line and that cabozantinib not only inhibits the VEGFR, but also c-MET, a target that is amplified in a large subgroup of papRCCs [12]. Also mostly in second or further line, Campbell et al. observed a PR rate of $12 \%$, and an estimated median timeon-treatment of 17.3 months in $17 \mathrm{~m}$-papRCC patients treated with cabozantinib. One-year survival after start of cabozantinib was at least $67 \%$ [20]. The reported outcome for m-papRCCs treated with VEGF-targeted therapies is clearly inferior to outcome reported with VEGFR-TKIs in m-ccRCCs. Motzer et al. showed a mPFS of 11 months for patients on first-line sunitinib as well as PR in $31 \%$ of patients. mOS was 26 months [21]. Similar results were 
Table 3

Comparison of outcome on VEGF-targeted therapies in metastatic papillary renal cell carcinoma in different trials or retrospective studies

\begin{tabular}{|c|c|c|c|c|c|}
\hline Study & Treatment & Number of patients & Median PFS(months) & Overall RR & Median OS(months) \\
\hline \multicolumn{6}{|l|}{ FIRST AGENT VEGFR-TKI } \\
\hline Tannir et al. [8] (ESPN) & Sunitinib & 14 & 5.7 & NR & 16.6 \\
\hline Armstrong et al. [6] (ASPEN) & Sunitinib & 33 & 8.1 & $24 \%$ & NR \\
\hline Choueiri et al. [5] & $\begin{array}{l}\text { Sorafenib }(68 \%) \\
\text { Sunitinib }(32 \%)\end{array}$ & 41 & 7.6 & $5 \%$ & NR \\
\hline Haaker et al. (present study) & $\begin{array}{l}\text { Sunitinib }(69 \%) \\
\text { Pazopanib }(20 \%) \\
\text { Sorafenib }(8 \%) \\
\text { Axitinib }(2 \%)\end{array}$ & 49 & 6.0 & $20 \%$ & 14.0 \\
\hline Ravaud et al. [7] (SUPAP) & Sunitinib & 61 & $\begin{array}{l}\text { Type } 2: 5.5 \\
\text { Type 1: } 6.6\end{array}$ & $\begin{array}{l}\text { Type } 2: 13 \% \\
\text { Type } 1: 11 \%\end{array}$ & $\begin{array}{l}\text { Type } 2: 12.4 \\
\text { Type } 1: 17.8\end{array}$ \\
\hline Connor-Wells [3] (IMDC) & $\begin{array}{l}\text { Sunitinib }(77 \%) \\
\text { Sorafenib }(16 \%) \\
\text { Pazopanib }(6 \%) \\
\text { Bevacizumab }(1 \%)\end{array}$ & 372 & 4.9 & $11.9 \%$ & 13.9 \\
\hline $\begin{array}{l}\text { TRIALS WITH } \\
\text { CABOZANTINIB, MOSTL } \\
\text { IN SECOND OR FURTHER } \\
\text { LINE }\end{array}$ & & & & & \\
\hline Martinez-Chanza et al. [12] & Cabozantinib & 66 & 6.6 (time-to-treatment failure) & $27 \%$ & $46 \%$ of 1 -year survival \\
\hline Campbell et al. [20] & Cabozantinib & 17 & $\begin{array}{l}17.3 \text { (time-on-treatment, as } \\
\text { calculated from data in table) }\end{array}$ & $12 \%$ & $>67 \%$ of 1 -year survival \\
\hline
\end{tabular}

PFS = progression-free survival; OS = overall survival; VEGF = vascular endothelial growth factor; VEGFR-TKI = vascular endothelial growth factor receptor tyrosine kinase inhibitor; $\mathrm{RR}=$ response rate.

found by Sternberg et al. for pazopanib, with mPFS of 11.1 months and a PR rate of $30 \%$ [22].

We confirmed the prognostic impact on OS of the IMDC risk classification in m-papRCC treated with VEGFR-TKIs. Similar results were found in the large IMDC cohort: mOS was 34.1 months in m-papRCC patients with good prognostic score, compared to 17.0 and 6.0 months in patients with intermediate and poor prognostic score, respectively $(P<$ 0.0001). In the IMDC cohort, patients with papRCC had less frequently an IMDC good risk $(12.0 \%$ vs. $20.0 \%)$ and a higher percentage of IMDC poor risk $(32.3 \%$ vs. $24.8 \%)$ as compared to ccRCC patients [3]. In our patient group, we also found that a large proportion of the patients (44.9\%) had a poor prognostic score at start of first agent VEGFRTKI, which is sign of the more aggressive character of this disease.

The incidence of BM at start of first agent VEGFR-TKIs was $36.7 \%$ in our series of m-papRCC patients. Graham et al. reported an incidence of BM of $36.4 \%$ in 319 mpapRCC patients with synchronous metastases at diagnosis [23]. Ravaud et al. observed an incidence of BM in $28 \%$ of $\mathrm{m}$-papRCC patients at start of first-line treatment [7].

Patients with BM who received concomitant BRIs had similar outcome as patients with BM who did not receive concomitant BRIs. Given the fact that the IMDC risk score was worse in patients treated with concomitant BRIs, it is possible that concomitant administration of BRIs might have given a small advantage in outcome. This would be in coherence with the hypothesis of Vrdoljak et al. [18] and with our own observations in m-ccRCC patients with BM [24].
In our series, BM were particularly frequent in type $2 \mathrm{~m}$ papRCC, and rare in type $1 \mathrm{~m}$-papRCC. First, we think that this observation needs to be confirmed in larger series. In order to explore the hypothesis that the presence of $\mathrm{BM}$ would be the driver of the more aggressive behavior of type 2 papRCCs, we included a bivariate analysis with the presence of BM and subtype of papRCC. Both the presence of $\mathrm{BM}$ as the subtype remained as independently associated with OS, which is an argument against this hypothesis.

Our study shows that the presence of BM has a negative prognostic impact in m-papRCC patients treated with VEGFR-TKIs. Previous analyses on m-ccRCC patients treated with first-line VEGFR-TKIs in large cohorts showed the negative prognostic impact of BM. An analysis by our own research group, including $223 \mathrm{~m}$-ccRCC patients who started first-line sunitinib, showed a significantly worse mPFS (8.2 vs. 19.1 months; $P<0.0001)$ and mOS (19.5 vs. 38.5 months; $P<0.0001$ ) [17]. Vrdoljak et al. found a mPFS of 8.1 vs. 10.8 months $(P=0.007)$ and a mOS of 14.1 vs. 22.0 months $(P<0.001)$ in their cohort of 4410 mRCC patients (of which $88.4 \%$ were ccRCC) [18]. In a series including $1059 \mathrm{mRCC}$ patients treated with sunitinib, a significantly worse mOS was observed in presence of BM (16.1 vs. 27.8 months, $P<0.0001)$. In the latter series, $97 \%$ of the patients had clear-cell and 3\% nonclear-cell histology [19]. Note that patients with BM had received more often $(33.3 \%$ vs. $6.5 \%)$ systemic therapy before first agent VEGFR-TKI compared to patients without BM, however, in most cases this was a short course of a mTOR inhibitor (everolimus or temsirolimus), known to have reduced 
activity in papRCC. In our series, the number of BM was not related to outcome, but patient numbers were too small for a reliable analysis.

The reason why RCC patients with BM have a poorer outcome is still unknown. More aggressive primary kidney tumors might have a higher spread to bones. Vrdoljak et al. showed a worse performance status when BM were present [18]. We could not replicate this in our current analysis. In a previous analysis on patients with m-ccRCC, we showed that patients with BM had earlier VEGFR-TKI dose reductions, which could influence outcome [25]. Time-to-firstdose-reduction as estimated by Kaplan-Meier in the group of patients with and without BM was similar. However, patient numbers are small for this kind of comparison. In the present analysis, BM were associated with a higher number of metastatic sites, thus a more important spread of the disease.

Few other prognostic biomarkers have been described in m-papRCC. In $25 \mathrm{~m}$-papRCC treated with sunitinib, sorafenib or temsirolimus, Karnofsky and Eastern Cooperative Oncology Group performance scores were found to be significantly correlated with 2-year OS. Patients who were treated by nephrectomy before systemic treatment appeared to have an advantage over those who were not. Previous inferior vena cava thrombectomy and lymph node resection as well as elevated lactate dehydrogenase and C-reactive protein and lower albumin were associated with shorter OS [26]. In a series of $41 \mathrm{~m}$-papRCC patients treated with sunitinib or sorafenib, baseline hemoglobin levels and time from diagnosis to start of systemic therapy were associated with mPFS [5].

We could not show any significant difference in outcome on VEGFR-TKIs between type 1 and type 2 papRCCs, a finding in accordance with literature. In the SUPAP trial with 62 patients, mPFS and mOS on sunitinib were longer in type 1 papRCC (6.6 months and 17.8 months, respectively), than in type 2 papRCC (5.5 months and 12.4 months, respectively), but these differences were not significant [7]. In 30 type 1 and 165 type 2 patients treated with various VEGF inhibitors (sunitinib, sorafenib, pazopanib, bevacizumab, or axitinib) or mTOR inhibitors (temsirolimus or everolimus), Connor Wells et al. found a mPFS of 7.7 vs. 4.3 months and a mOS of 20.0 vs. 12.6 months for type 1 and type 2 papRCC, respectively. Again, these differences were not significant [3]. Finally, in a study on 92 patients treated with the mTOR inhibitor everolimus, mPFS and mOS for type 1 papRCC were higher (7.9 and 28.0 months, respectively) than for type 2 (5.1 and 24.2 months, respectively), though not significantly [27].

The strength of our study is that it includes a homogeneous series of $49 \mathrm{~m}$-papRCC patients, with histology reviewed by expert genito-urinary pathologists, all receiving first agent VEGFR-TKIs. Our study is one of the few studies that has described prognostic biomarkers in this rare disease.
However, our study also has several weaknesses. First of all, it is a retrospective study. We could not study the impact of baseline C-reactive protein [26,28] levels and the percentage of sarcomatoid dedifferentiation [29] due to missing values and hence low patient numbers. The prognostic impact of BM in m-papRCC patients treated with immune checkpoint inhibitors or c-MET-inhibitors such as cabozantinib might be different and should be studied in patients treated with these therapies. It would also be interesting to study the impact of the presence of BM in $\mathrm{m}$ papRCC in ongoing prospective trials such as the Calypso trial combining the cMET-inhibitor savolitinib with the immune checkpoint inhibitor durvalumab (NCT02819596).

\section{Conclusion}

In m-papRCC patients treated with first agent VEGFRTKIs, the presence of $\mathrm{BM}$ is a negative prognostic factor for outcome.

\section{Conflicts of interest}

Benoit Beuselinck received an unrestricted research grant from Bristol-Myers-Squibb and honorarium from Merck, Pfizer, Bristol-Myers-Squibb, Ipsen and Astra Zeneca. Stéphane Oudard received honorarium from Merck, Pfizer, Bristol-Myers-Squibb, Bayer, Roche and Sanofi. Philip Debruyne received honorarium from Merck, Bristol-Myers-Squibb, Bayer, Roche, Astra Zeneca and Sanofi. Brigitte Laguerre received honoraria and travel support for meetings from Novartis, Pfizer, Bristol-MyersSquibb and MSD.

\section{References}

[1] Bray F, Ferlay J, Soerjomataram I, Siegel RL, Torre LA, Jemal A. Global cancer statistics 2018: GLOBOCAN estimates of incidence and mortality worldwide for 36 cancers in 185 countries. CA Cancer J Clin 2018;68(6):394-424.

[2] Patard JJ, Leray E, Rioux-Leclercq N, Cindolo L, Ficarra V, Zisman A, et al. Prognostic value of histologic subtypes in renal cell carcinoma: a multicenter experience. J Clin Oncol 2005;23(12):2763-71.

[3] Connor Wells J, Donskov F, Fraccon AP, Pasini F, Bjarnason GA, Beuselinck B, et al. Characterizing the outcomes of metastatic papillary renal cell carcinoma. Cancer Med 2017;6(5):902-9.

[4] Motzer RJ, Bacik J, Mariani T, Russo P, Mazumdar M, Reuter V. Treatment outcome and survival associated with metastatic renal cell carcinoma of non-clear-cell histology. J Clin Oncol 2002;20 (9):2376-81

[5] Choueiri TK, Plantade A, Elson P, Negrier S, Ravaud A, Oudard S, et al. Efficacy of sunitinib and sorafenib in metastatic papillary and chromophobe renal cell carcinoma. J Clin Oncol 2008;26(1):127-31.

[6] Armstrong AJ, Halabi S, Eisen T, Broderick S, Stadler WM, Jones RJ, et al. Everolimus versus sunitinib for patients with metastatic non-clear cell renal cell carcinoma (ASPEN): a multicentre, openlabel, randomised phase 2 trial. Lancet Oncol 2016;17(3):378-88.

[7] Ravaud A, Oudard S, De Fromont M, Chevreau C, Gravis G, Zanetta $\mathrm{S}$, et al. First-line treatment with sunitinib for type 1 and type 2 locally advanced or metastatic papillary renal cell carcinoma: a phase 
II study (SUPAP) by the French Genitourinary Group (GETUG)dagger. Annals Oncol 2015;26(6):1123-8.

[8] Tannir NM, Plimack E, Ng C, Tamboli P, Bekele NB, Xiao L, et al. A phase 2 trial of sunitinib in patients with advanced non-clear cell renal cell carcinoma. Eur Urol 2012;62(6):1013-9.

[9] Choueiri TK, Plimack E, Arkenau HT, Jonasch E, Heng DYC, Powles T, et al. Biomarker-based phase II trial of savolitinib in patients with advanced papillary renal cell cancer. J Clin Oncol 2017;35(26):2993-3001.

[10] Schoffski P, Wozniak A, Escudier B, Rutkowski P, Anthoney A, Bauer S, et al. Crizotinib achieves long-lasting disease control in advanced papillary renal-cell carcinoma type 1 patients with MET mutations or amplification. EORTC 90101 CREATE trial. Eur J Ccancer 2017;87:147-63.

[11] Choueiri TK, Vaishampayan U, Rosenberg JE, Logan TF, Harzstark AL, Bukowski RM, et al. Phase II and biomarker study of the dual MET/VEGFR2 inhibitor foretinib in patients with papillary renal cell carcinoma. J Clin Oncol 2013;31(2):181-6.

[12] Martinez Chanza N, Xie W, Asim Bilen M, Dzimitrowicz H, Burkart J, Geynisman DM, et al. Cabozantinib in advanced non-clear-cell renal cell carcinoma: a multicentre, retrospective, cohort study. Lancet Oncol 2019;20(4):581-90.

[13] McGregor BA, McKay RR, Braun DA, Werner L, Gray K, Flaifel A, et al. Results of a multicenter phase II study of atezolizumab and bevacizumab for patients with metastatic renal cell carcinoma with variant histology and/or sarcomatoid features. J Clin Oncol 2020;38 (1):63-70.

[14] Waldert M, Haitel A, Marberger M, Katzenbeisser D, Ozsoy M, Stadler E, et al. Comparison of type I and II papillary renal cell carcinoma (RCC) and clear cell RCC. BJU Int 2008;102(10):1381-4.

[15] Heng DY, Xie W, Regan MM, Warren MA, Golshayan AR, Sahi C, et al. Prognostic factors for overall survival in patients with metastatic renal cell carcinoma treated with vascular endothelial growth factor-targeted agents: results from a large, multicenter study. J Clin Oncol 2009;27(34):5794-9.

[16] Kroeger N, Xie W, Lee JL, Bjarnason GA, Knox JJ, Mackenzie MJ, et al. Metastatic non-clear cell renal cell carcinoma treated with targeted therapy agents: characterization of survival outcome and application of the International mRCC Database Consortium criteria. Cancer 2013;119(16):2999-3006.

[17] Beuselinck B, Oudard S, Rixe O, Wolter P, Blesius A, Ayllon J, et al. Negative impact of bone metastasis on outcome in clear-cell renal cell carcinoma treated with sunitinib. Annals Oncol 2011;22(4):794800 .

[18] Vrdoljak E, Gore M, Leyman S, Szczylik C, Kharkevich G, Schoffski $\mathrm{P}$, et al. Bisphosphonates in patients with renal cell carcinoma and bone metastases: a sunitinib global expanded-access trial subanalysis. Future Oncol 2015;11(20):2831-40.

[19] Motzer RJ, Escudier B, Bukowski R, Rini BI, Hutson TE, Barrios $\mathrm{CH}$, et al. Prognostic factors for survival in 1059 patients treated with sunitinib for metastatic renal cell carcinoma. Br J Cancer 2013;108 (12):2470-7.

[20] Campbell MT, Bilen MA, Shah AY, Lemke E, Jonasch E, Venkatesan AM, et al. Cabozantinib for the treatment of patients with metastatic non-clear cell renal cell carcinoma: A retrospective analysis. Eur J Cancer 2018;104:188-94.

[21] Motzer RJ, Hutson TE, Tomczak P, Michaelson MD, Bukowski RM, Rixe O, et al. Sunitinib versus interferon alfa in metastatic renal-cell carcinoma. New Engl J Med 2007;356(2):115-24.

[22] Sternberg CN, Davis ID, Mardiak J, Szczylik C, Lee E, Wagstaff J, et al. Pazopanib in locally advanced or metastatic renal cell carcinoma: results of a randomized phase III trial. J Clin Oncol 2010;28 (6):1061-8.

[23] Graham J, Wells JC, Donskov F, Lee JL, Fraccon A, Pasini F, et al. Cytoreductive nephrectomy in metastatic papillary renal cell carcinoma: results from the International Metastatic Renal Cell Carcinoma Database Consortium. Eur Urol Oncol 2019;2(6):643-8.

[24] Beuselinck B, Wolter P, Karadimou A, Elaidi R, Dumez H, Rogiers A, et al. Concomitant oral tyrosine kinase inhibitors and bisphosphonates in advanced renal cell carcinoma with bone metastases. Br J Cancer 2012;107(10):1665-71.

[25] Haaker L, De Meue E, Wildiers H, Verbiest A, Dumez H, Lerut E, et al. Bone metastases and age are associated with earlier dose reductions in metastatic clear-cell renal cell carcinoma patients treated with angiogenesis inhibitors. Acta Clin Belg 2018:1-10.

[26] Ito H, Shioi K, Murakami T, Takizawa A, Sano F, Kawahara T, et al. $\mathrm{C}$-reactive protein in patients with advanced metastatic renal cell carcinoma: usefulness in identifying patients most likely to benefit from initial nephrectomy. BMC Cancer 2012;12:337.

[27] Escudier B, Molinie V, Bracarda S, Maroto P, Szczylik C, Nathan P, et al. Open-label phase 2 trial of first-line everolimus monotherapy in patients with papillary metastatic renal cell carcinoma: RAPTOR final analysis. Eur J Cancer 2016;69:226-35.

[28] Beuselinck B, Vano YA, Oudard S, Wolter P, De Smet R, Depoorter L, et al. Prognostic Impact of Baseline Serum C-Reactive Protein in Metastatic Renal Cell Carcinoma Patients Treated With Sunitinib. BJU Int 2014;114(1):81-9.

[29] Beuselinck B, Lerut E, Wolter P, Dumez H, Berkers J, Van Poppel H, et al. Sarcomatoid Dedifferentiation in Metastatic Clear Cell Renal Cell Carcinoma and Outcome on Treatment With Anti-Vascular Endothelial Growth Factor Receptor Tyrosine Kinase Inhibitors: A Retrospective Analysis. Clin Genitourin Cancer 2014;12(5):e205-14. 